\title{
GIANT THROMBUS ENTRAPPED BY A PATENT FORAMEN OVALE IN A PATIENT WITH POLYCYSTIC KIDNEY DISEASE
}

\author{
Gustavo Neves de Araujo', Stéfani Mariani², Felipe Pereira Lima Marques', \\ Lucas Simonetto Faganello ${ }^{1}$, Luis Henrique Klafke ${ }^{1}$, \\ Douglas Dal Mas Freitas ${ }^{1}$, Solano Berger ${ }^{1}$
}

Clin Biomed Res. 2017;37(2):140-142

1 Cardiology Service, Hospital de Clínicas de Porto Alegre. Porto Alegre, RS, Brazil.

2 Medical School, Universidade Federal do Rio Grande do Sul (UFRGS). Porto Alegre, RS, Brazil.

Corresponding author: Stéfani Mariani stefani.mariani22@gmail.com Medical School, Universidade Federal do Rio Grande do Sul (UFRGS) Av. Jerônimo de Ornelas, 721 . 90040-341, Porto Alegre, RS, Brazil.

\section{ABSTRACT}

Polycystic kidney disease (PKD) is the most common genetic cause of chronic kidney disease (CKD). The most common cause of death in patients with this condition is cardiovascular disease, mainly due to hypertension and its consequences. We report a case of a 42-year-old male patient with polycystic kidney disease who developed a giant thrombus entrapped by a patent foramen ovale after an acute myocardial infarction.

Keywords: Acute myocardial infarction; patent foramen ovale; thrombus-in-transit

Thrombus straddling the patent foramen ovale is a rare situation, usually developed after venous thrombi migrate from the deep venous system of the lower extremities or from the pelvic veins, in a setting of hypercoagulable states, such as chronic kidney disease ${ }^{1,2}$. When untreated, thrombus-in-transit can lead to pulmonary or paradoxical systemic embolism. The optimal treatment is unknown, and the options include anticoagulation, thrombolysis, and surgical removal $^{3}$. We report a case of a patient with polycystic kidney disease who developed a giant thrombus entrapped by a patent foramen ovale after an acute myocardial infarction.

\section{CASE REPORT}

A 42-year-old male patient with a history of depression, hypertension, and chronic kidney disease (CKD) due to polycystic kidney disease (PKD) was admitted at the psychiatry division due to suicidal ideation. Fifteen days after admission the patient had severe chest pain during routine hemodialysis session, and prompt ECG was performed. Diagnosis of anterior ST-Segment elevation (V1-V4) myocardial infarction was made, and the patient was urgently transferred to the catheterization laboratory. Coronary angiography evidenced an aneurysm in proximal anterior descendent artery with a thrombotic occlusion distally in the same vessel (figure 1A). Coronary angioplasty was performed with angiographic success. Transesophageal echocardiography (figures 2A-2C) showed a large intracardiac thrombus, which began in the superior vena cava, entered the right atrium, crossed to the left atrium through a patent foramen ovale, and penetrated the left ventricle. Anticoagulation was prescribed, and because there were minimal changes in thrombus size after 7 days of therapy, surgery was performed. The procedure consisted of mechanical removal of the thrombus and closure of the foramen ovale. It had no complications, with successful thrombus removal (figure 2D). The post-operative period was well tolerated, and the patient was discharged asymptomatic after reaching target prothrombin time using warfarin. Follow-up was performed in outpatient visits, and six months after discharge he was free of adverse events.

\section{DISCUSSION}

Polycystic kidney disease (PKD) is the most common genetic cause of $\mathrm{CKD}^{1}$. Hepatic cysts are the most common extra-renal manifestation of the disease, and complementary evaluation of our patient showed a large number 


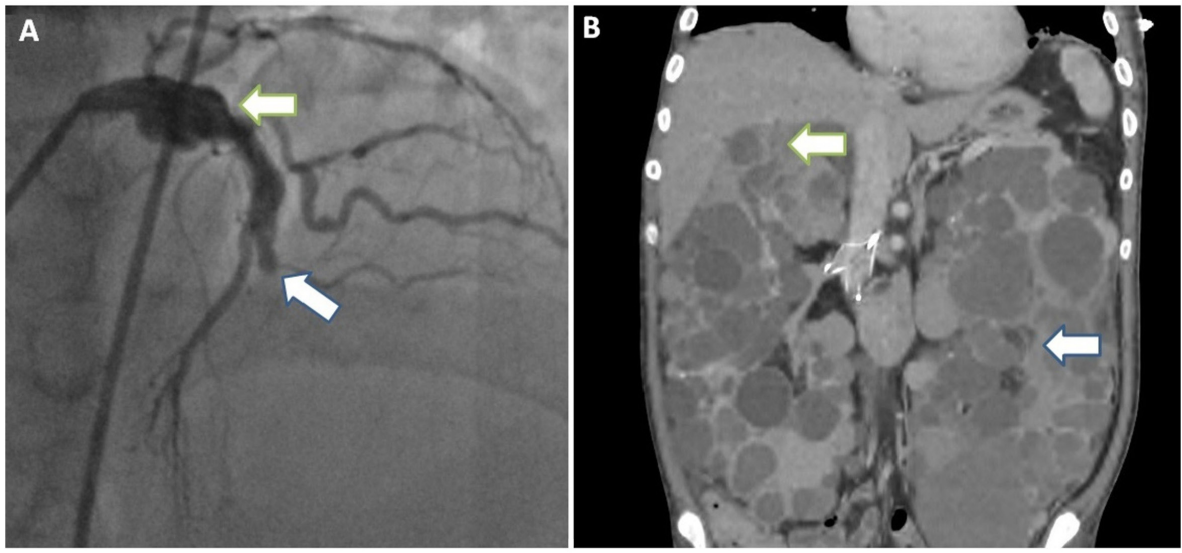

Figure 1: (A) Anterior Descendent coronary aneurism (green arrow) and a thrombotic occlusion distally in the same artery (blue arrow); (B) Hepatic and renal cysts in abdominal cavity (green and blue arrow, respectively).
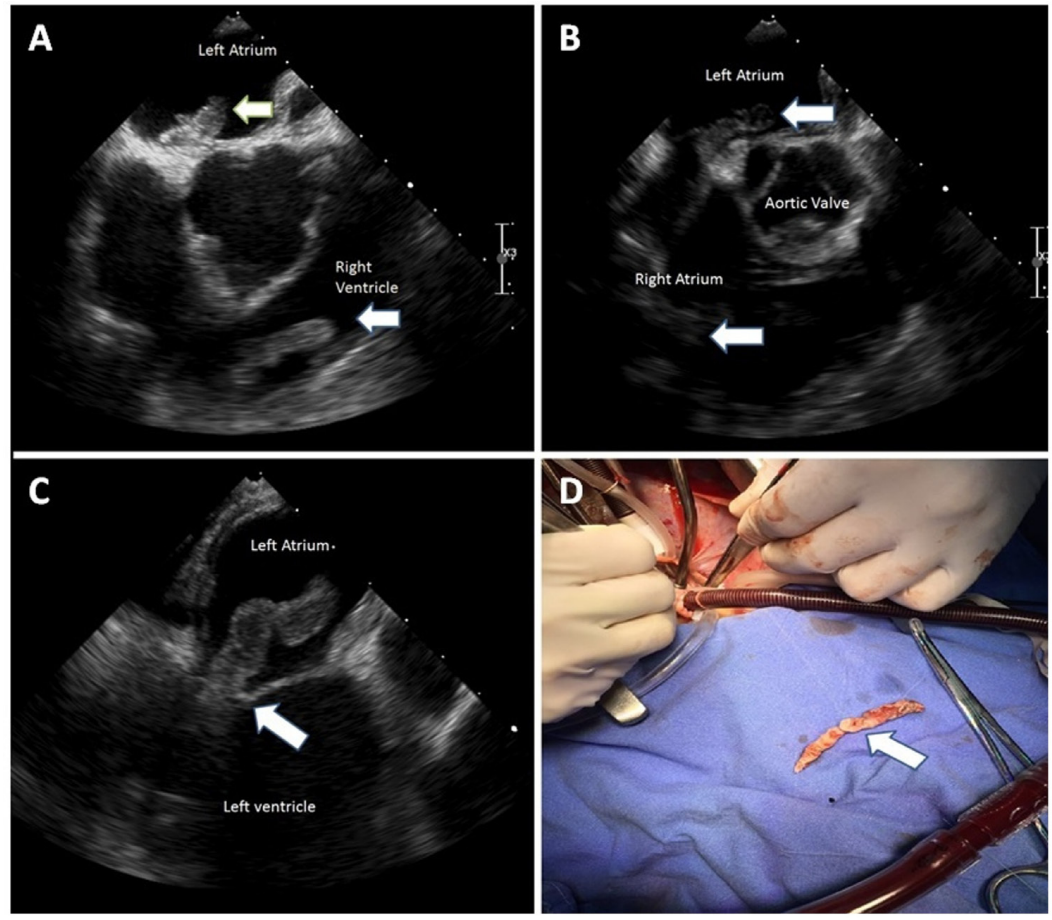

Figure 2: (A, B and C) Transesophageal echocardiography showing a giant thrombus (arrows) within all cardiac chambers; (D) Surgically removed thrombus.

of cysts within his liver and kidney (figure 1B). The most common cause of death is cardiovascular disease, mainly due to hypertension and its consequences.

To our knowledge, this is the first case of thrombus-in-transit of a patient with PKD. This condition is associated with risk factors such as cancer and hypercoagulability states ${ }^{2}$. Factors involved in intracardiac thrombus formation in our patient probably included a hypercoagulability state caused by CKD and PKD, as well as heightened inflammatory response and further hemodynamic instability caused by the acute myocardial infarction.

There is no consensus about the best treatment strategy, and prior reports have described successful management with both surgery and anticoagulation ${ }^{3}$. If anticoagulation successfully removes the thrombus, percutaneous closure of the patent foramen ovale could be an option, although this strategy has not been described. In most reported cases, patients undergo surgical removal. 


\section{REFERENCES}

1. Kasper DL, Fauci AS, Longo DL, Hauser SL, Jameson JL, Loscalzo J. Harrison's principles of internal medicine. 18th ed. United States: McGraw Hill; 2015.

2. Aggarwal K, Jayam VK, Meyer MA, Nayak AK, Nathan S.
Thrombus-in-transit and paradoxical embolism. J Am Soc Echocardiogr. 2002;15(9):1021-2. http://dx.doi. org/10.1067/mje.2002.121279.

PMid:12221427

3. Shah DP, Min JK, Raman J, Lodato JA, Van Kley D, Lang RM, et al.
Thrombus-in-transit: two cases and a review of diagnosis and management. J Am Soc Echocardiogr. 2007;20(10):1219.e6-8. http://dx.doi. org/10.1016/j.echo.2007.01.041. PMid:17583475

Received: Feb 16, 2017 Accepted: Apr 18, 2017 